\title{
Development of traffic noise prediction model for major arterial roads of tier-II city of India (Surat) using artificial neural network
}

https://doi.org/10.1515/noise-2021-0013

Received Aug 13, 2020; accepted Mar 16, 2021

\begin{abstract}
In the issue of expanding noise levels the world over, road traffic noise is main contributor. The investigation of street traffic noise in urban communities is a significant issue. Ample opportunity has already passed to understand the significance of noise appraisal through prediction models with the goal that assurance against street traffic noise can be actualized. Noise predictions models are utilized in an increasing range of decision-making applications. This study's main objective is to assess ambient noise levels at major arterial roads of Surat city, compare these with prescribed standards, and develop a noise prediction model for arterial roads using an Artificial Neural Network. The feed-forward back propagation method has been used to train the model. Models have been developed using the data of three roads separately, and one final model has also been developed using the data of all three roads. Among the prediction in three arterial roads, the predicted output result from the model of Adajan-Rander showed a better correlation with a mean squared error (MSE) of 0.789 and $\mathrm{R}^{2}$ value of 0.707 . But with the combined model, there is a slight deterioration in mean squared value (MSE) 1.550, with $\mathrm{R}^{2}$ not getting changed much significantly, i.e., 0.755 . However, the combined model's prediction can be adopted due to the variety of data used in its training.
\end{abstract}

Keywords: prediction model, arterial roads, road traffic noise, ANN

\footnotetext{
${ }^{\star}$ Corresponding Author: Ramesh B. Ranpise: Civil Engineering Department, Sardar Vallabhbhai National Institute of Technology, Ichchhanath, Surat-395007 Gujarat, India;

Email: ranpiseramesh6588@gmail.com

B. N. Tandel, Vivek A. Singh: Civil Engineering Department, Sardar Vallabhbhai National Institute of Technology, Ichchhanath, Surat395007 Gujarat, India
}

\section{Introduction}

Noise arises from manmade activities, especially the expansion and improvement of transport and industry [1]. Road transport is an essential contributor to the economic development and growth of a country [2]. Road network plays a significant role in the development of a nation. But on the other hand, it creates a noisy environment and affects humans and the surrounding environment [3]. Road traffic noise is a combination of sounds from tire-pavement interaction, engine noise, aerodynamic and braking element, road surface, horn honking, tire rolling noise, acceleration, deceleration, etc. [4-7]. Noise is getting more and more omnipresent, yet a disregarded shape of infection even in advanced international locations.

Road traffic noise is the most comprehensive source of ambient outdoor noise pollution in Europe [8-10]. Arterial roads in a city play several roles within the suburb and are a fundamental element of the transportation network that carries a wide range of private and public vehicles [11].

Generally, road traffic, heavy vehicles, machinery, jet planes, building equipment, manufacturing processes, and lawnmowers are significant sources of these unwanted sounds regularly sent into the ambient environment [12]. Though noise pollution is a slow and indistinct killer, very less effort has been made to ameliorate. Along with other pollution types, it has become a hazard to life quality [13, 14]. Traffic noise significantly affects physical as well as mental health and labor productivity, and it is a significant source of noise in an urban environment [15].

The noise produced from the interaction of vehicular tires and the road surface is a main contributor to the total traffic noise [5, 16-18].

Noise may cause disturbance, disrupt sleep, hypertension, and hinder cognitive development in children $[1,14$, $19,20]$. The effects of extreme noise could be so severe that there is a permanent loss of memory or a psychiatric disorder [21]. Hence, there are many adverse effects [9] of excessive noise or acute exposure to noise.

๖ Open Access. ๑ 2021 R. B. Ranpise et al., published by De Gruyter. (cc) BY 4.0 License 
Environmental noise predictions are helpful in increasing scope of decision-making applications, generally for assessments where a decision is to be made regarding the future change to an environmental noise field [19, 22, 23].

Traffic noise prediction models have a difference in parameters and may produce different noise level estimates depending on the geographical condition [8].

Mine and Sevtap developed a model which predicts the annoyance level due to road traffic noise. They considered social aspects, urban development, and traffic characteristics. These models provide cost-efficient action plans since they help understand the aspect that directly affect annoyance levels [24]. ANN model was competent in identifying the relations. The distance from the road's boundary is also the main contributing factor, whereas heavy-vehicle volume was unexpectedly found to be minimum [25]. Agarwal and Swami developed an experimental noise prediction model for evaluating equivalent noise levels $\left(\mathrm{L}_{e q}\right)$; in respect of equivalent traffic density number under diversified traffic flow conditions, the author concluded that traffic noise depends on traffic flow present on roads [26]. Rajakumara et al. developed an empirical traffic noise prediction model in the scattered traffic flow conditions. They concluded that road traffic noise is a significant concern of people living in road networks in urban areas. This study helps assess the environmental consequences of road traffic noise during interrupted traffic flow conditions in urban areas of Indian cities [7]. Sonaviya and Tandel developed correction factor applying a mathematical model for road traffic noise prediction for a interrupted traffic flow [27].

The prediction model can help to maintain the acoustic environment [28]. In this research work, artificial neural network technique has been used to expand a prediction model for fundamental arterial roads of Surat metropolis due to its abilities of mastering via examples with a wide variety and give short effects in contrast to other strategies.

This study's main objective is to assess ambient noise levels at major arterial roads of Surat city, compare these with prescribed standards, and develop a noise prediction model for arterial roads using ANN.

\section{Material and methodology}

The methodology followed for collecting field data such as traffic volume, traffic noise levels, vehicle spot speed, major arterial roads of Surat city, and instruments used in this study such as sound level meter, radar gun, and fieldwork has been narrated in subsequent sections.

\subsection{Study area}

For this research work, Surat city has been selected as the study area. Surat city is located in the western part of India in the state of Gujarat. The geographical location of Surat city is $210^{\circ} 12^{\prime} 00.00^{\prime \prime} \mathrm{N}$ and $72^{\circ} 52^{\prime} 00.00^{\prime \prime} \mathrm{E}$ near the bank of river Tapi. Surat is now the tenth-largest city of India, having an estimated population of 5million. The city is connected by road, rail and air transport. Some National and State Highways pass through the edge of the city. Thus, traffic coming to and as going through the city is very high. The city transportation framework is dominatingly road based.

Three arterial roads have been selected for the detailed survey based on the land use alongside the roads of Surat city. Amongst the selected roads, one is Athwa-Dumas road, one of the busiest roads in Surat. Many multi-story buildings, shopping complexes, restaurants are there alongside the road. It also connects the Surat airport to the city. The second is Adajan-Rander road. It is also an important arterial road that connects different villages and main centers in the city. The third one is Udhna-Sachin road; this is also an important road that connects to the city with the industrial hub Sachin. Hence, this road consistently contains high noise levels even in the off-peak hours because of the industrial activities.

\subsection{Selection of location}

While selecting the study location, some points are considered. The sampling point should not be near the intersection, the monitoring point should be selected at a straight stretch of road, and the traffic flow should be uninterrupted. Monitoring points should be far from public places like schools, colleges, courts, hospitals, etc.

\subsection{Traffic noise measurement}

Noise level readings were collected for each minute interval for a continuous $24 \mathrm{hrs}$. ( $\mathrm{L}_{e q, 24 h r s .}$ ) by using the Larson \& Davis System 824 sophisticated sound level meter (SLM 824) and real-time analyzer. It has versatile capabilities with a rugged and user-friendly package. The sound level meter was held at about 1.5 meters above the ground near the road's edge. 


\subsection{Traffic characteristics and geometrical dimensions of road measurement}

It comprises traffic flow conditions, traffic volume, and average spot speed of vehicles. Handycam was used for recording the videos continuously for $24 \mathrm{hrs}$. After that, the traffic was counted by playing the videos, i.e., manual counting for different vehicle categories. Average speed for different vehicle types was measured by a radar gun, i.e., on-spot measurement. Road width was measured by meter tape \& average building height was measured by counting the floors. (Assuming 1 floor $=3$ meter). After the collection of data, a model has been developed using Artificial Neural Network in MATLAB software.

\subsection{Assumption made in the study}

The following assumption are composed in this study, within the practical limit, without any loss of generality:

i. Traffic noise is quantifiable by the equivalent noise, Leq. with A weightage.

ii. The road stretch is linear and levelled with a reasonably good road surface condition, and therefore the effect of variation in road interface is negligible.

iii. 2-W in this model means all types of motorized twowheelers, irrespective of engine capacity, i.e. $100 \mathrm{cc}$, $110 \mathrm{cc}, 125 \mathrm{cc}, 150 \mathrm{cc}, 180 \mathrm{cc}$.

iv. 3-W in this model means all types of motorized threewheelers, irrespective of engine capacity, i.e. $100 \mathrm{cc}$, $110 \mathrm{cc}, 125 \mathrm{cc}, 150 \mathrm{cc}, 180 \mathrm{cc}$.

v. 4-W in this model means all types of motorized fourwheelers, irrespective of engine capacity, i.e. $800 \mathrm{cc}$, $1000 \mathrm{cc}, 1200 \mathrm{cc}, 1400 \mathrm{cc}$, and so on.

vi. There is no barrier, either manmade or natural or, between the observer and noise source. (i.e., traffic flow).

vii. The model is applied under ideal meteorological conditions, i.e., no significant influence of wind, temperature, humidity, and rainfall.

viii. There are two forms of vehicle motion, such as cruising with steady uniform speed and stopping.

ix. All the vehicles moving on roadways in the study locations fulfil the Indian Motor Vehicle Rules-1989.

$\mathrm{x}$. It is supposed that the environmental noise level due to vehicular motor traffic to a first approximation is a function of the traffic volume (composition) only.

\section{Analysis of data}

Data have been collected in the pilot survey and detailed survey, including noise level readings, classified traffic volume count, average vehicle speed, road width, and average building height at three selected arterial roads. The distance from the edge of the road is also main contributing factor, whereas heavy-vehicle volume was found to be the least.

\subsection{Pilot survey}

In the pilot study, data have been collected for one hour in each period, i.e., peak (morning \& evening) and off-peak period (afternoon), to overview the noise and traffic pattern in that area.

Details of this pilot survey are enumerated as under:

(a) In this survey, readings were taken for three periods, i.e., morning \& evening peak periods and afternoon off-peak periods ( $1 \mathrm{hr}$ for each period) at all three roads.

(b) Noise level readings (dBA) (each minute reading for $1 \mathrm{hr}$.).

(c) Categorized traffic volume count of one-way traffic, i.e., two-wheeler, three-wheeler, four-wheeler \& Heavy vehicles (15 min interval, for $1 \mathrm{hr}$.

(d) Average speed measurements of one-way traffic for these vehicles ( $15 \mathrm{~min}$. interval, for $1 \mathrm{hr}$.)

(e) Width of the lane and average building height near the collection point.

\subsection{Detailed study}

For a detailed analysis, the noise measurement was done for continuous 24 hours, starting from 9.00 am morning to the next morning $9.00 \mathrm{am}$; readings were collected every minute for better accuracy and a large dataset. From this selected three arterial roads, Athwa-Dumas road, probably the busiest road, and the other two are significant major arterial roads that associate distinctive peri-urban zones and principle focus to the city. The determination of these roads emerged from the way that they have high traffic volume. 


\section{(A) Athwa-Dumas road}

Observations for Athwa-Dumas road

\section{4-Hrs. TRAFFIC VOLUME COUNT}

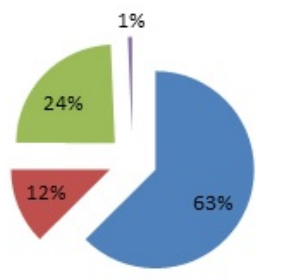

ATHWA-DUMAS

Figure 1: Traffic composition at Athwa-Dumas road

Table 1: Traffic composition

\begin{tabular}{ccc}
\hline Type of vehicles & Volume & Count \\
\hline & Nos. & \%age \\
\hline 2w & 52813 & 62.55 \\
3w & 10569 & 12.51 \\
4W & 20494 & 24.27 \\
H.V. & 554 & 0.65 \\
\hline Total & 84430 & 100 \\
\hline
\end{tabular}

It can be seen from the chart that the contribution of different vehicle categories to the noise is as follows:

$$
2-w(63 \%)<4-w(24 \%)<3-w(12 \%)<H . V .(1 \%)
$$

It is visible in the graph that the significant contribution to the noise levels is due to the 2-w. This road, located in a posh area, has higher numbers of 4-w count (24\%). Hence, this heterogeneity of traffic 2-w and 4-w (combined 87\%) leads to congestion on roads, increasing traffic noise. From 9.00 am to $9.15 \mathrm{pm}$, the noise has an increasing trend. The maximum noise is $76.7 \mathrm{dBA}$ at $9.15 \mathrm{pm}$. After that point, it starts decreasing due to the decreasing number of vehicles till $6.15 \mathrm{am}$. The minimum noise is 66.7 at $6.15 \mathrm{am}$. After that, it again starts increasing.

\section{(B) Adajan-Rander road}

Observations for Adajan-Rander Road

\section{4-Hrs. TRAFFIC VOLUME COUNT}

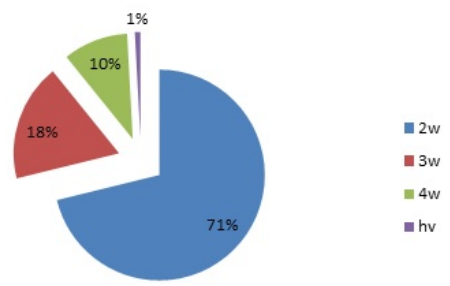

Figure 3: Traffic composition at Adajan-Rander road

Table 2: Traffic composition

\begin{tabular}{ccc}
\hline Type of vehicles & $\begin{array}{c}\text { Volume } \\
\text { Nos. }\end{array}$ & $\begin{array}{c}\text { Count } \\
\text { \%age }\end{array}$ \\
\hline $2 \mathrm{w}$ & 38939 & 71.16 \\
$3 \mathrm{w}$ & 9858 & 18.01 \\
$\mathrm{w} w$ & 5448 & 9.95 \\
H.V. & 469 & 0.85 \\
\hline Total & 54714 & 100 \\
\hline
\end{tabular}

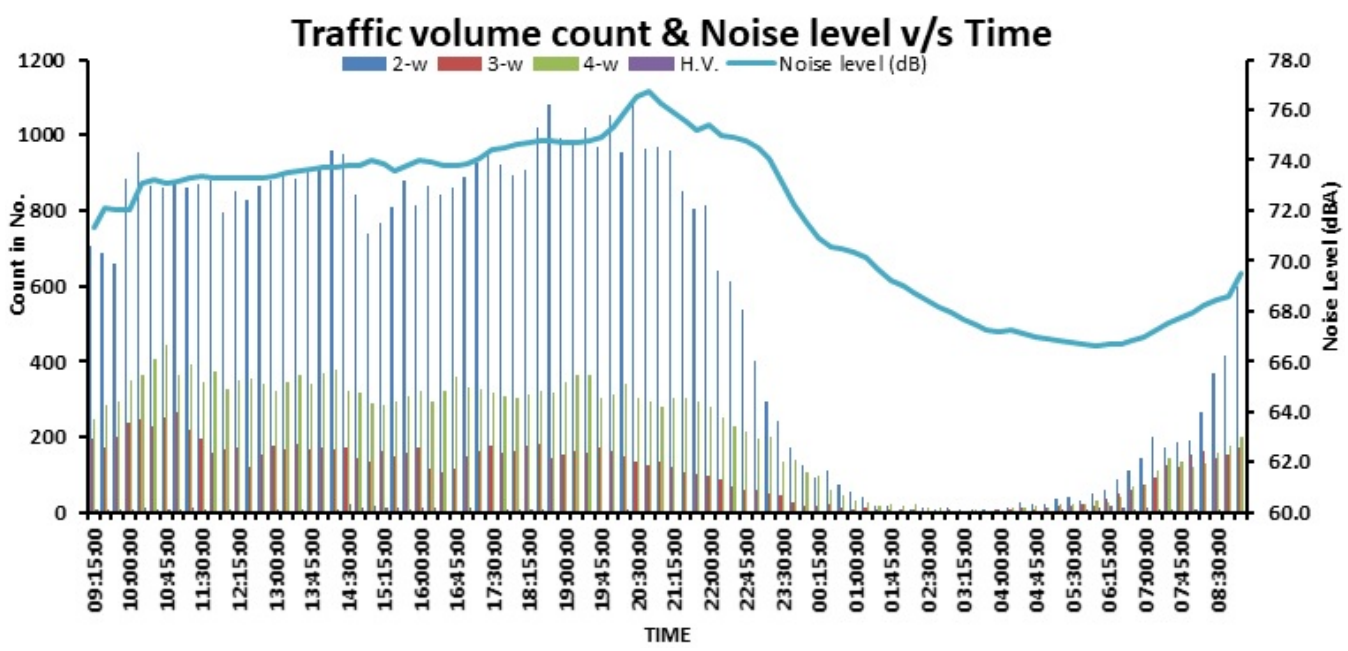

Figure 2: Graphical representation of noise level and traffic volume during $24 \mathrm{hrs}$. at Athwa-Dumas road 


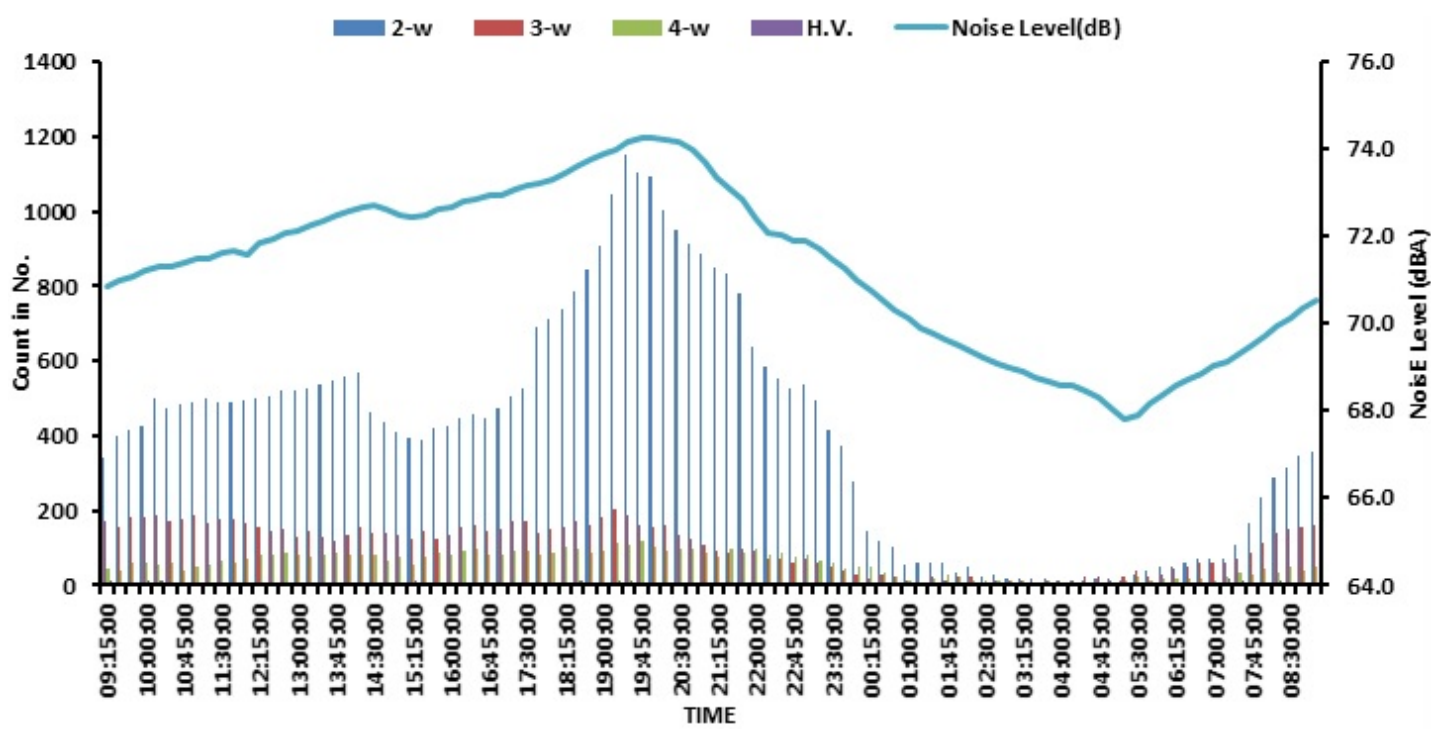

Figure 4: Graphical representation of noise level and traffic volume during $24 \mathrm{hrs}$. at Adajan-Rander road

At Adajan-Rander, the contribution to the noise of different categories of vehicle is as follows:

$$
\begin{aligned}
2-w(71.16 \%) & <3-w(18.01 \%)<4-w(9.95 \%) \\
& <H . V .(0.85 \%)
\end{aligned}
$$

The noise levels in the Adajan-Rander road are less in comparison to Athwa-Dumas road. Also, the traffic volume on this road is less even in the peak hours. The maximum noise level at this road is $74.3 \mathrm{dBA}$ at $7.45 \mathrm{pm} \&$ the lowest value is $67.8 \mathrm{dBA}$ at $5.30 \mathrm{am}$. This $\mathrm{L}_{\max }$ is nearly $2.5 \mathrm{~dB}$, lesser than Athwa-Dumas arterial road.

(C) Udhna-Sachin road

Observations for Udhan-Sachin road

Table 3: Traffic composition

\begin{tabular}{ccc}
\hline Type of vehicles & $\begin{array}{c}\text { Volume } \\
\text { Nos. }\end{array}$ & $\begin{array}{c}\text { Count } \\
\text { \%age }\end{array}$ \\
\hline $2 \mathrm{w}$ & 41772 & 65.73 \\
$3 \mathrm{w}$ & 13168 & 20.72 \\
$4 \mathrm{~W}$ & 8065 & 12.69 \\
H.V. & 540 & 0.84 \\
\hline Total & 63545 & 100 \\
\hline
\end{tabular}

\section{4-Hrs. TRAFFIC VOLUME COUNT}

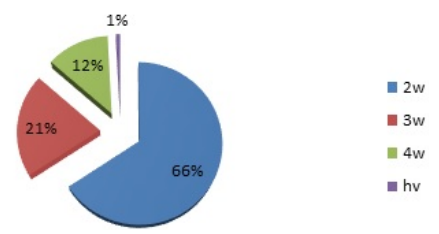

Figure 5: Traffic composition at Udhna-Sachin road

At Udhna-Sachin road, contribution to the noise of different categories of vehicle is as follows:

$$
\begin{aligned}
2-w(65.73 \%) & <3-w(20.72 \%)<4-w(12.69 \%) \\
& <H . V .(0.84 \%)
\end{aligned}
$$

This arterial road has a peculiar traffic count of max 2-W and a higher 3-w (Autorickshaw). The reason, this being a majorly industrial area, working people class MIG and EWS prefer para-transit mode of transportation, i.e., 3-w (autorickshaw).

It is visible in this graph, as shown in Figure 6, that the rate at which noise level is increasing is almost the same until $8.45 \mathrm{pm}$, where the maximum value is $74.7 \mathrm{dBA}$. Also, the traffic volume increase rate is nearly stable till $8.30 \mathrm{pm}$, after that the number of vehicles is getting reduced, and near about after $5.30 \mathrm{am}$, it again started increasing. 


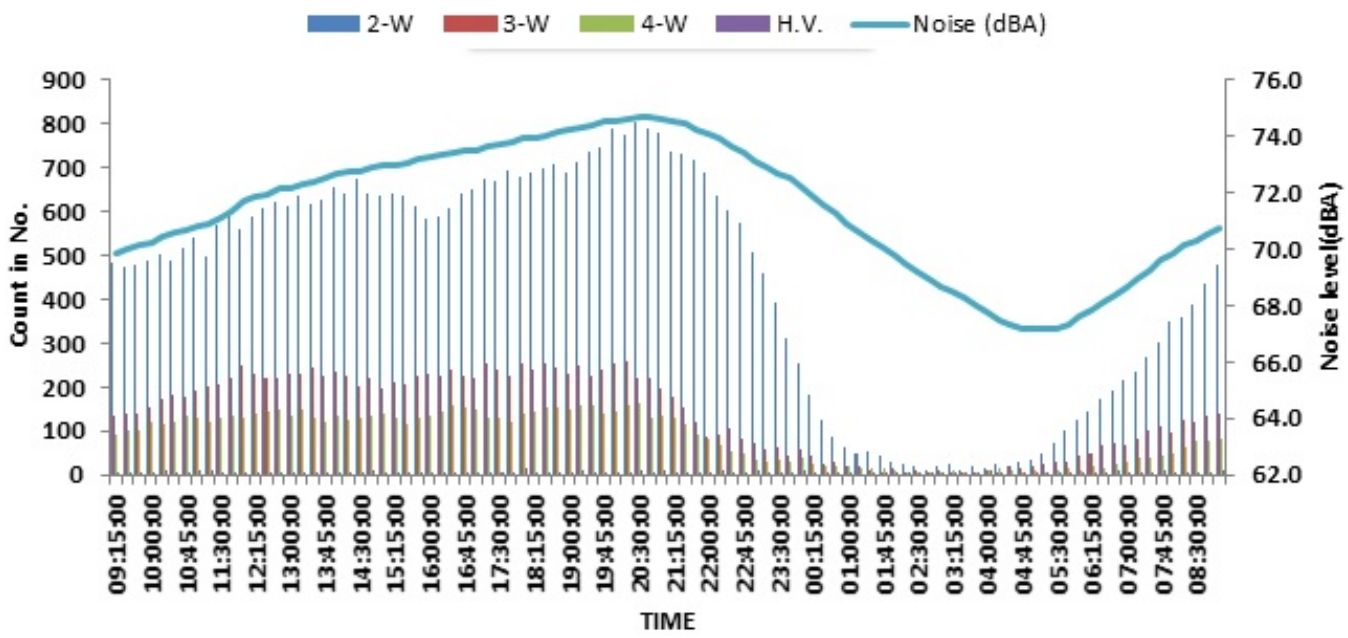

Figure 6: Graphical representation of noise level and traffic volume during $24 \mathrm{hrs}$. at Udhna-Sachin road

\section{Model development}

After the data has been collected, the process of model development starts. An ANN model has been developed with the help of the collected data in the detailed study. MATLAB R2012a (7.14.0.739) has been used to create the model. In MATLAB, Neural Network Toolbox has been used to develop and run the developed model to predict the output values. Data has been normalized first to avoid the overflow of the network due to very large or small weights and to eliminate the effect of different input variables influence. Data have been normalized in the range of $[0,1]$ by the following formula:

$$
X_{\text {norm. }}=\frac{\left(X_{i}-X_{\min .}\right)}{\left(X_{\max }-X_{\min .}\right)}
$$

The data cannot directly be used in the raw excel form in MATLAB. To use them, the data have to be converted into Mfile. After making M-files, data managers must be opened to import the M-files (INPUT, TARGET) and create the network. In this Data manager, all the decisions regarding creating the network have to be made, i.e., Network type, training function, performance function, learning function, transfer function, number of neurons in the hidden layer, etc.
There is no hard \& fast rule for deciding the number of neurons for the network. Neurons can only be determined by the trial and error method. The network has been developed with a different number of neurons, and the best number has been chosen based on MSE with those combinations. The table of MSE \& $\mathrm{R}^{2}$ with a different number of neurons is given below:

\section{(A) For Athwa-Dumas road}

\section{No. of neurons $v / s$ MSE}

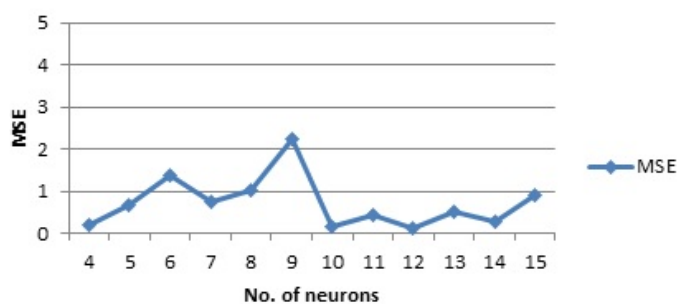

Figure 7: Graph between MSE \& number of neurons

Table 4: Network functions

\begin{tabular}{|c|c|c|c|c|c|}
\hline Network Type & Training Function & Learning function & $\begin{array}{l}\text { Performance } \\
\text { function }\end{array}$ & $\begin{array}{c}\text { Number of } \\
\text { Neurons }\end{array}$ & Transfer function \\
\hline $\begin{array}{l}\text { Feed-forward } \\
\text { back } \\
\text { propagation }\end{array}$ & TRAINLM & LEARNGDM & MSE & 11 & TANSIG \\
\hline
\end{tabular}


Table 5: Selection of neurons

\begin{tabular}{cccc}
\hline $\begin{array}{c}\text { Number of } \\
\text { neurons }\end{array}$ & $\begin{array}{c}\text { Mean squared } \\
\text { error }\end{array}$ & $\mathbf{R}^{\mathbf{2}}$ value & $\begin{array}{c}\text { Number of } \\
\text { epochs }\end{array}$ \\
\hline 4 & 0.212 & 0.971 & 13 \\
5 & 0.655 & 0.960 & 19 \\
6 & 1.369 & 0.947 & 12 \\
7 & 0.75 & 0.962 & 10 \\
8 & 1.039 & 0.935 & 15 \\
9 & 2.239 & 0.841 & 21 \\
10 & 0.167 & 0.971 & 23 \\
11 & 0.419 & 0.952 & 49 \\
12 & 0.138 & 0.984 & 24 \\
13 & 0.527 & 0.950 & 27 \\
14 & 0.257 & 0.980 & 19 \\
15 & 0.918 & 0.847 & 31 \\
\hline
\end{tabular}

A different number of neurons from 4 to 15 have been tried to develop the model, but the least MSE was obtained at 12. That's why; the number of neurons for the network has been fixed at 12 . The MSE and $\mathrm{R}^{2}$ at 12 are $0.138 \& 0.984$, respectively.

\section{(B) For Adajan-Rander road}

Table 6: Selection of neurons

\begin{tabular}{cccc}
\hline $\begin{array}{c}\text { Number of } \\
\text { neurons }\end{array}$ & $\begin{array}{c}\text { Mean squared } \\
\text { error }\end{array}$ & $\mathbf{R}^{\mathbf{2}}$ value & $\begin{array}{c}\text { Number of } \\
\text { epochs }\end{array}$ \\
\hline 4 & 0.284 & 0.979 & 21 \\
5 & 0.255 & 0.981 & 27 \\
6 & 0.197 & 0.987 & 19 \\
7 & 0.992 & 0.814 & 20 \\
8 & 0.799 & 0.873 & 25 \\
9 & 0.066 & 0.981 & 28 \\
10 & 1.280 & 0.812 & 35 \\
11 & 0.723 & 0.952 & 29 \\
12 & 0.539 & 0.973 & 22 \\
13 & 0.219 & 0.982 & 33 \\
14 & 0.347 & 0.959 & 22 \\
15 & 0.309 & 0.971 & 21 \\
\hline
\end{tabular}

The minimum value of MSE is 9. Therefore, the optimum number of neurons for the prediction model of AdajanRander road would be 9 . The value of $R^{2}$ at this point is 0.981.

The value of MSE varies from 0.066 to 1.280 , with neurons ranging from 4 to 15.

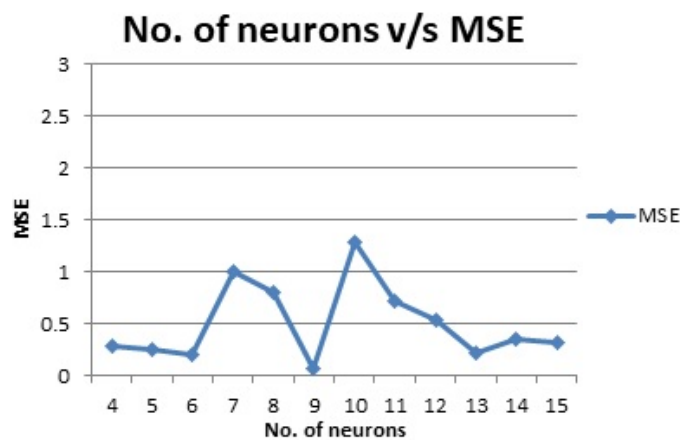

Figure 8: Graph between MSE \& number of neurons

(C) For Udhna-Sachin road

Table 7: Selection of neurons

\begin{tabular}{cccc}
\hline $\begin{array}{c}\text { Number of } \\
\text { neurons }\end{array}$ & $\begin{array}{c}\text { Mean squared } \\
\text { error }\end{array}$ & $\mathbf{R}^{\mathbf{2}}$ value & $\begin{array}{c}\text { Number of } \\
\text { epochs }\end{array}$ \\
\hline 4 & 0.480 & 0.942 & 29 \\
5 & 0.827 & 0.909 & 23 \\
6 & 0.452 & 0.953 & 34 \\
7 & 0.379 & 0.968 & 21 \\
8 & 0.251 & 0.981 & 26 \\
9 & 0.930 & 0.892 & 21 \\
10 & 0.721 & 0.932 & 35 \\
11 & 0.301 & 0.947 & 27 \\
12 & 0.124 & 0.971 & 19 \\
13 & 0.256 & 0.963 & 30 \\
14 & 1.108 & 0.872 & 39 \\
15 & 0.812 & 0.921 & 28 \\
\hline
\end{tabular}

No. of neurons v/s MSE

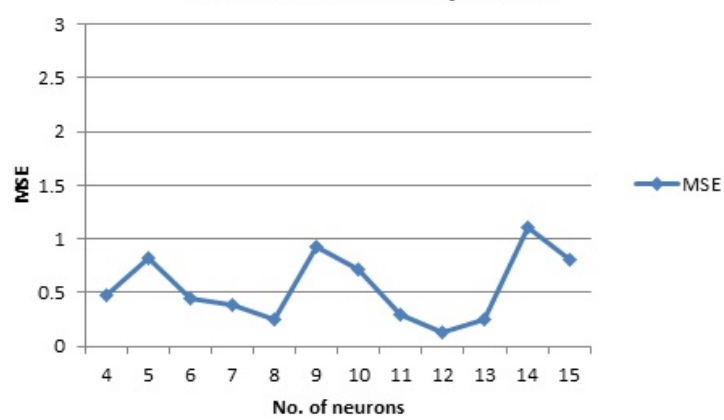

Figure 9: Graph between MSE \& number of neurons

For Udhna-Sachin road, the minimum value of MSE is 0.124 , which comes with 12 neurons. Therefore 12 neu- 
rons have been fixed for the hidden layer in the model. The corresponding $\mathrm{R}^{2}$ value at this point is 0.971 .

\section{(D) For all the three roads}

Table 8: Selection of neurons

\begin{tabular}{cccc}
\hline $\begin{array}{c}\text { Number of } \\
\text { neurons }\end{array}$ & $\begin{array}{c}\text { Mean squared } \\
\text { error }\end{array}$ & $\mathbf{R}^{\mathbf{2}}$ value & $\begin{array}{c}\text { Number of } \\
\text { epochs }\end{array}$ \\
\hline 4 & 0.306 & 0.965 & 17 \\
5 & 0.412 & 0.967 & 8 \\
6 & 0.458 & 0.956 & 7 \\
7 & 0.398 & 0.96 & 3 \\
8 & 0.258 & 0.975 & 10 \\
9 & 0.436 & 0.973 & 3 \\
10 & 0.347 & 0.962 & 4 \\
11 & 0.022 & 0.97 & 10 \\
12 & 0.362 & 0.969 & 13 \\
13 & 0.641 & 0.967 & 11 \\
14 & 0.577 & 0.967 & 7 \\
15 & 0.521 & 0.965 & 9 \\
\hline
\end{tabular}

A different number of neurons from 4 to 15 have been tried to develop the model, but the least MSE was obtained at 11. That's why the number of neurons for the network has been fixed at 11 . The MSE and $R^{2}$ at 11 are $0.022 \& 0.970$, respectively.

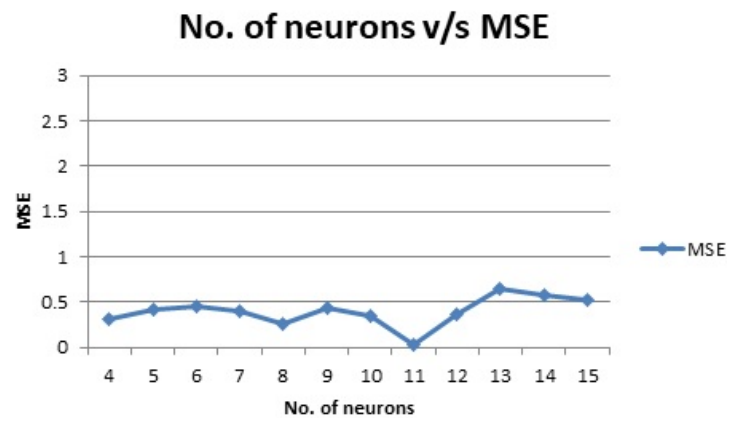

Figure 10: Graph between MSE \& number of neurons

\section{Training of network}

After selecting the different functions and neurons, the network is needed to be trained with the inputs. Here the feedforward back propagation network has been used. Therefore, for training, the desired output in the form of a Target matrix is required to feed the network. In this study, the numbers of inputs are $10 \&$ the output is 1 . So, the structure of the network will be the same as given in Figure 11.

The real data has been divided into the following parts:

1) Training: (70\%)

These are presented to the network during training, and the network is adjusted conforming to its error.

2) Validation: (15\%)

These are used to compute network generalization and to halt training when generalization stops improving.

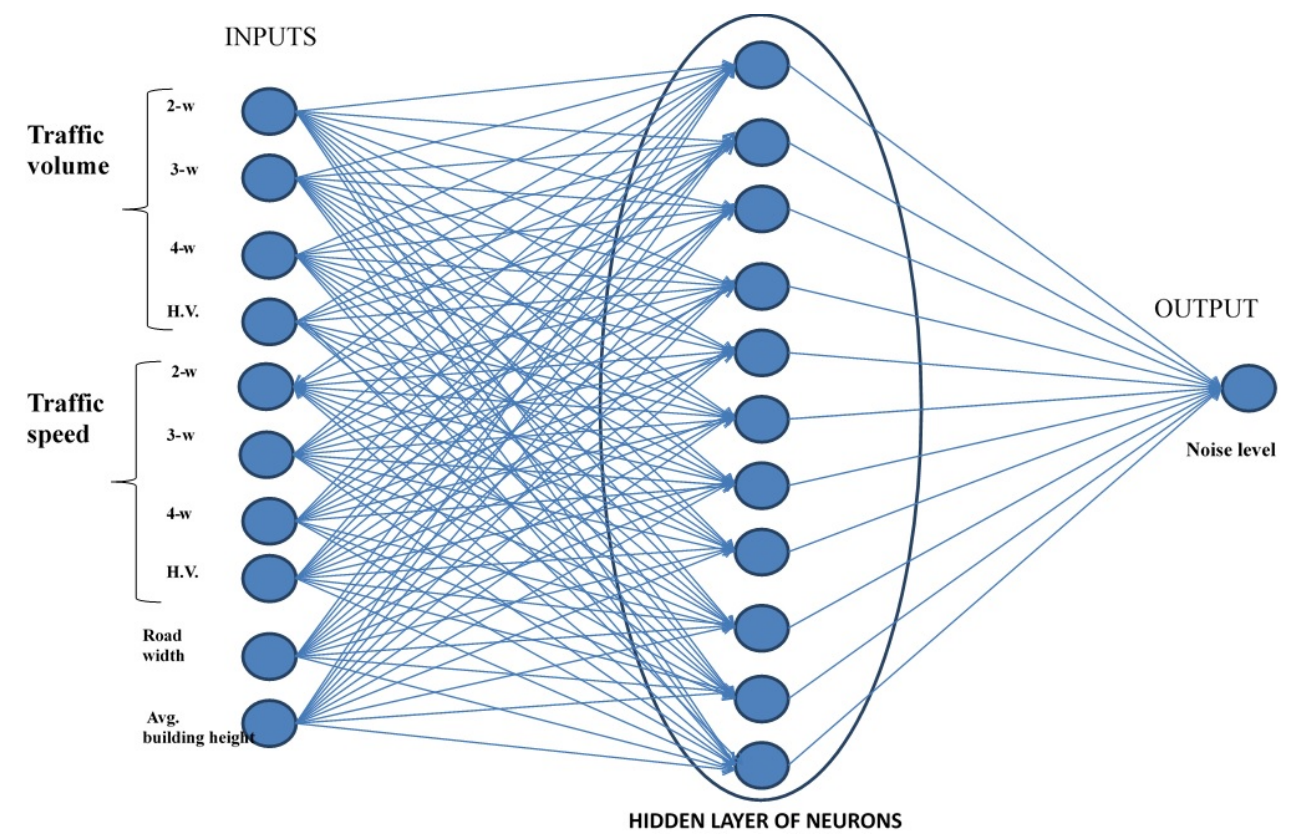

Figure 11: Structure of the Network 
Table 9: Range of different parameters for the combined model

\begin{tabular}{|c|c|c|c|c|c|c|c|c|c|c|c|}
\hline \multirow[t]{2}{*}{ Value } & \multirow{2}{*}{$\begin{array}{l}\text { Noise Level } \\
\text { (15 min.) } L_{e q A}\end{array}$} & \multicolumn{4}{|c|}{ Traffic volume count (15 min.) } & \multicolumn{4}{|c|}{ Avg. Traffic speed $(\mathrm{km} / \mathrm{h})$} & \multirow{2}{*}{$\begin{array}{c}\text { Road } \\
\text { width (m.) }\end{array}$} & \multirow{2}{*}{$\begin{array}{l}\text { Building } \\
\text { Ht. (m) }\end{array}$} \\
\hline & & $2-w$ & $3-w$ & 4-w & H.V. & $2-w$ & $3-w$ & 4-w & H.V. & & \\
\hline Max. & 76.7 & 1154 & 264 & 445 & 24 & 40 & 31 & 42 & 28 & 17 & 15 \\
\hline Min. & 66.6 & 6 & 2 & 2 & 0 & 28 & 20 & 21 & 0 & 7.5 & 9 \\
\hline
\end{tabular}

\section{3) Testing: (15\%)}

These do not influence training and give an independent measure of network performance during and after training [29].

\section{Results and discussions}

The accuracy of the network can be assessed by the MSE \& $R^{2}$ [30]. If the value of MSE is near zero, the model is generally considered acceptable. If $R^{2}$ value is near about 1 , the relation between input \& output parameters is considered good.

\section{(A) For Athwa-Dumas road}
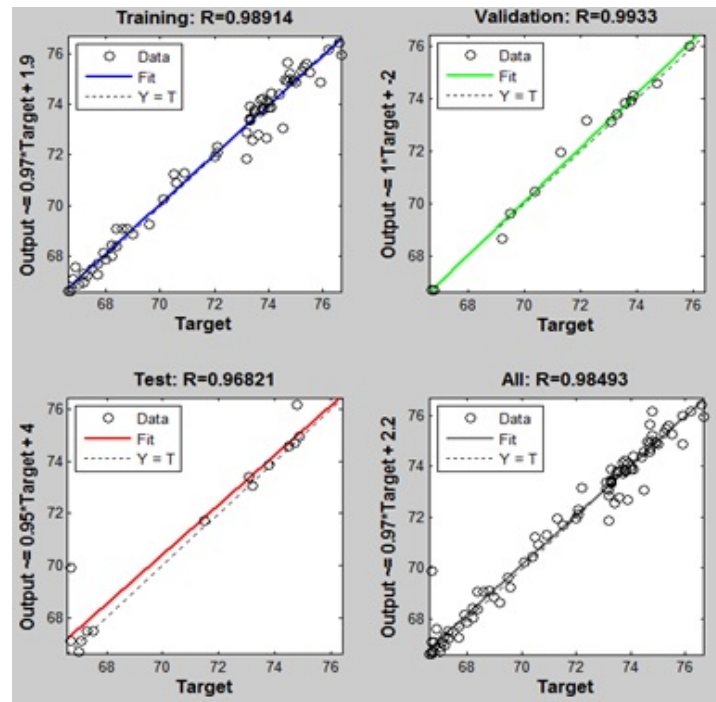

Figure 12: $R^{2}$ value graph of training, validation, and test of AthwaDumas road

The model developed using Athwa-Dumas road readings gives $\mathrm{MSE}=0.138$ and $\mathrm{R}^{2}=0.984$ in training and $\mathrm{MSE}=2.40$ and $\mathrm{R}^{2}=0.516$ in prediction.

\section{(B) For Adajan-Rander road}
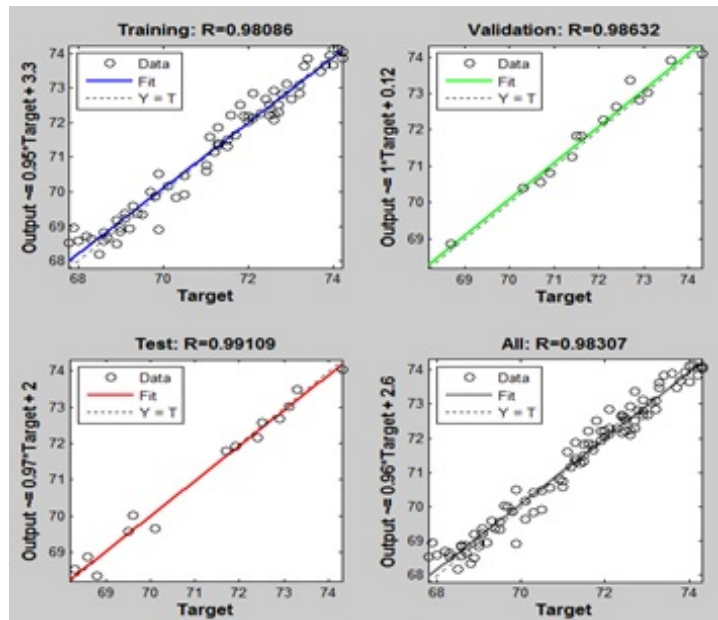

Figure 13: $R^{2}$ value graph of training, validation, and test of AdajanRander road

Adajan-Rander road, MSE $=0.066$ and $\mathrm{R}^{2}=0.981$ in training and MSE $=0.789$ and $\mathrm{R}^{2}=0.707$ in prediction

\section{(C) For Udhna-Sachin road}
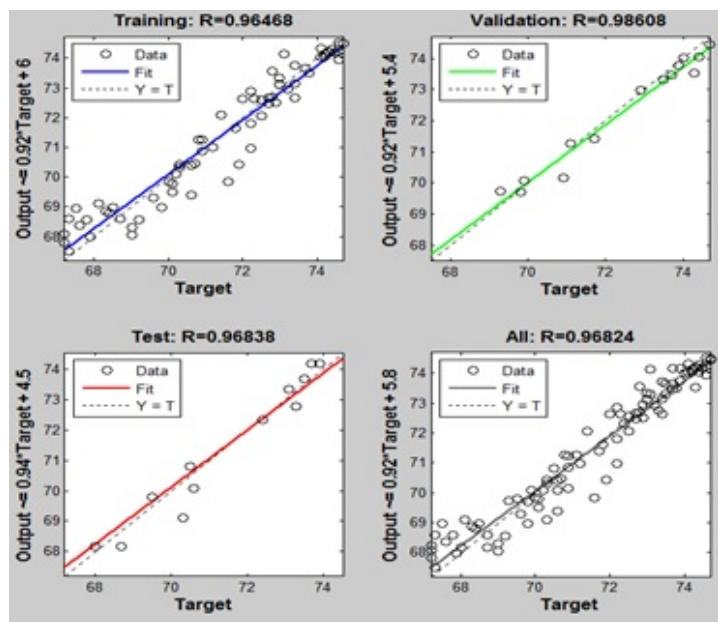

Figure 14: $R^{2}$ value graph of training, validation, and test of UdhnaSachin road 
Finally, for Udhna-Sachin road, MSE $=0.124$ and $\mathrm{R}^{2}=0.971$ in training and MSE $=1.25, \mathrm{R}^{2}=0.651$ in prediction

\section{(D) For all the three roads (combined)}

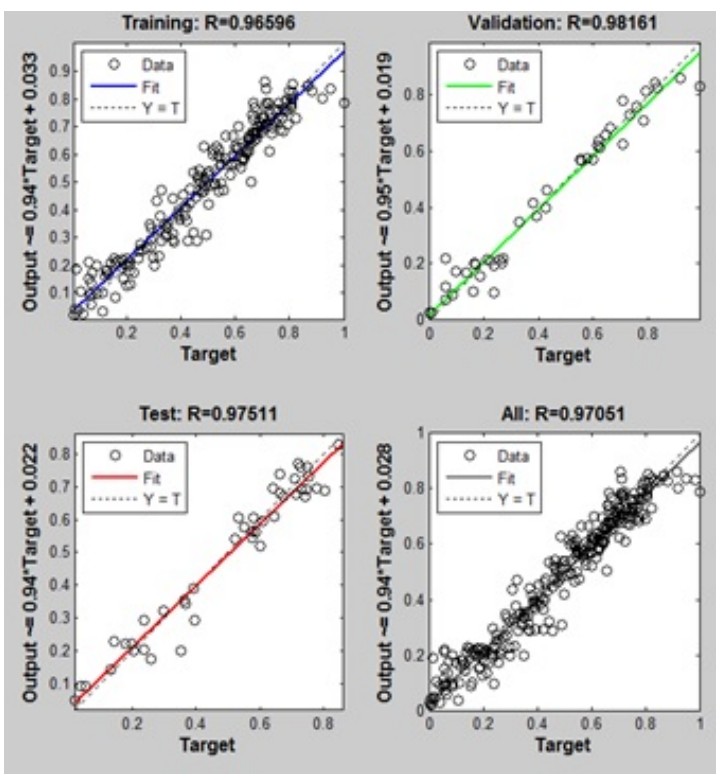

Figure 15: $\mathrm{R}^{2}$ value graph of training, validation, and test of all three roads

Hence, amongst all the three individual prediction models, Adajan-Rander road results are better because they give less MSE and better $\mathrm{R}^{2}$ values. The reason may be due to the same type of land use, i.e., commercial along the entire corridor. Also, one more reason for better MSE and $\mathrm{R}^{2}$ value for Adajan-Rander road might be the homogeneous nature of traffic and hence lesser $\mathrm{L}_{e q}$ values as compared to other two arterial roads. For the other two corridors, i.e. Athwa-Dumas and Udhna-Sachin corridors, having mixed land use, which may be the reason for slightly weaker MSE and $\mathrm{R}^{2}$ values.

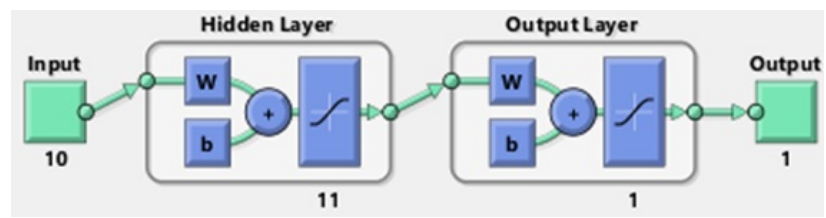

Figure 16: Developed Neural Network

\section{Model Validation}

Models have been developed using data of Athwa-Dumas road, Adajan-Rander road, and Udhna-Sachin road separately. A final model has also been developed using all the three road data combined. After that, the prediction of noise levels at another road (Adajan-Hazira road) has been made using these four models.

\section{(A) Prediction at Adajan-Hazira road using the model of Athwa-Dumas road}

\section{OBSERVED v/s PREDICTED VALUES}

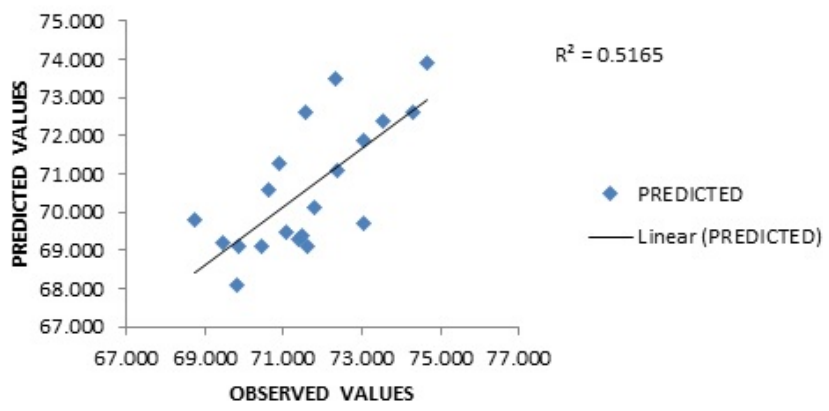

Figure 17: Observed v/s Predicted values at Adajan-Hazira road

\section{Adajan-Rander road}

Prediction at Adajan-Hazira road using the model of

\section{OBSERVED v/s PREDICTED VALUES}

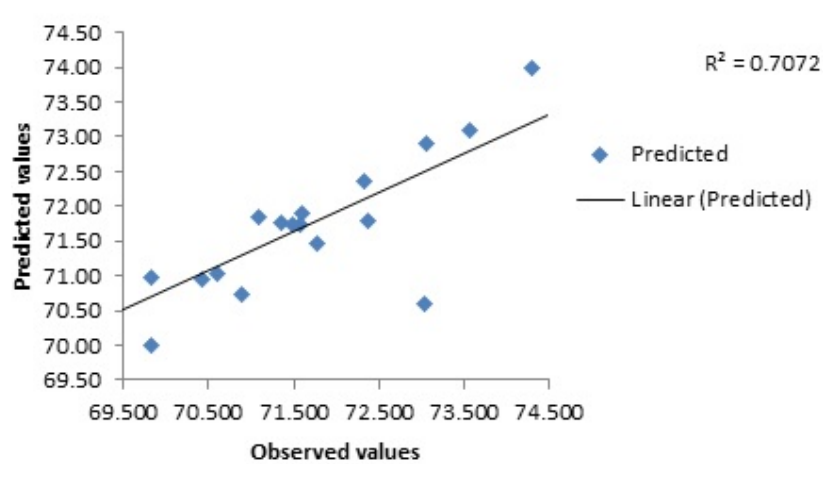

Figure 18: Observed v/s Predicted values at Adajan-Hazira road 
(C) Prediction at Adajan-Hazira road using the model of Udhna-Sachin road

\section{OBSERVED v/s PREDICTED VALUES}

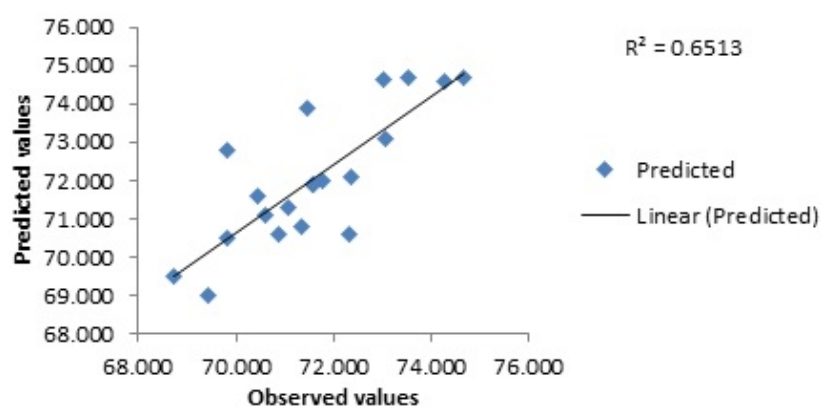

Figure 19: Observed v/s Predicted values at Adajan-Hazira road

(D) Prediction at Adajan-Hazira road using the model of all three roads

\section{OBSERVED v/s PREDICTED VALUES}

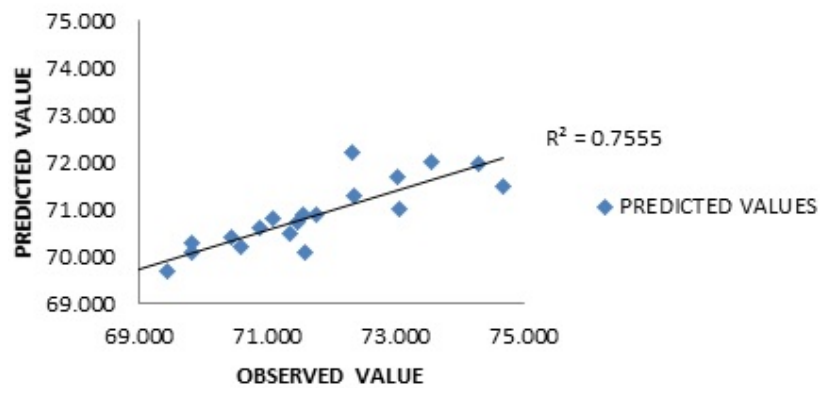

Figure 20: Observed v/s Predicted values at Adajan-Hazira road

Among all the prediction results, results obtained by the Adajan-Rander road and combined model are better. They are showing less MSE and better $\mathrm{R}^{2}$ values.

Amongst all three individual models developed, the model of Adajan-Rander road gives the best results when validated. Among the prediction in three arterial roads, the predicted output value from the model of Adajan-Rander showed a better correlation with a mean squared error (MSE) of 0.789 and $\mathrm{R}^{2}$ value of 0.707 . It may be due to the same type of land use in the Adajan-Rander zone. But with the combined model, there is a slight deterioration in mean squared value (MSE) 1.550, with $\mathrm{R}^{2}$ not getting changed much significantly, i.e., 0.755 . However, the combined model's prediction can be adopted due to the variety of data used in its training. The developed prediction model can be successfully applied to any arterial roads of tier-II cities of India, with a predominant commercial land use.

Table 10: Training results

\begin{tabular}{lcc}
\hline Model developed by using readings of & MSE & $\mathbf{R}^{\mathbf{2}}$ \\
\hline Athwa-Dumas road & 0.138 & 0.984 \\
Adajan-Rander road & 0.066 & 0.981 \\
Udhna-Sachin road & 0.124 & 0.971 \\
Combined & 0.022 & 0.979 \\
\hline
\end{tabular}

Table 11: Prediction results

\begin{tabular}{lcc}
\hline Model developed by using readings of & MSE & $\mathbf{R}^{\mathbf{2}}$ \\
\hline Athwa-Dumas road & 2.401 & 0.516 \\
Adajan-Rander road & 0.789 & 0.707 \\
Udhna-Sachin road & 1.252 & 0.651 \\
Combined & 1.550 & 0.755 \\
\hline
\end{tabular}

\section{Model limitation}

Individual models for all three arterial roads and the combined model have been validated, giving reasonable output accuracy. But one drawback of this model development process is that it provides no clue which variable is more influential. It also does not provide any equation regarding the correlation between the variables. It directly provides us with the output results by arranging weights between neurons. ANN-based traffic noise prediction model can also be developed by including more input variables, i.e., road surface type, meteorological factors like wind speed, humidity, temperature, etc.

\section{Conclusions}

The major aim of this study is to develop and optimize noise prediction model for arterial roads of a city in the developing country like India, using noise emission equivalency. Noise and traffic data have been collected for a continuous $24 \mathrm{hrs}$. at three different arterial roads of Surat city for developing a traffic noise prediction model. The real data has been divided into $15 \mathrm{~min}$. Interval. The model has been developed by the Artificial Neural Network toolbox in MATLAB software. The entire data set has undergone the necessary ANN process of training (70\%), validation (15\%), 
and testing (15\%). The developed model has ten input variables and one output variable. There is one hidden layer with eleven numbers of neurons.

At all three arterial roads understudy, the noise levels during day time and night time are above the permissible norms of Noise Pollution (Regulation and Control) Rules, 2000. Model developed by using Athwa-Dumas road readings gives $\mathrm{MSE}=0.138$ and $\mathrm{R}^{2}=0.984$ in training and MSE $=2.40$ and $R^{2}=0.516$ in prediction, for Adajan-Rander road, MSE $=0.066$ and $\mathrm{R}^{2}=0.981$ in training and $\mathrm{MSE}=0.789$ and $\mathrm{R}^{2}=0.707$ in prediction and finally for Udhna-Sachin road, MSE $=0.124$ and $R^{2}=0.971$ in training and MSE $=1.25$, $\mathrm{R}^{2}=0.651$ in prediction. Hence, amongst all the three individual prediction model results obtained by the Adajan-Rander road, it is better due to the same land-use type. It gives less MSE and better $\mathrm{R}^{2}$ values, whereas in the combined model, there is a slight deterioration in mean squared value (MSE) 1.550 , with $\mathrm{R}^{2}$ not getting changed much significantly, i.e., 0.755. However, the combined model's prediction can be adopted due to the variety of data used in its training. One of the drawbacks of this ANN model is that it gives no clue that it is a more influential variable. It also does not provide any equation regarding the correlation between the variables. The factors not considered in this study, but contributing to the generation and absorption of noise are vegetation along the roadside and the number of heavy vehicles passed through the road at afternoon 1:00 pm to 5:00 pm. To improve the MSE and $\mathrm{R}^{2}$ value, traffic noise models may be optimized using evolutionary computing tools like genetic algorithm. Also, only three independent variables have been taken into consideration such as vehicular speed, count and building height, but reduction and generation of noise levels also depends on vegetation along road, honking of horns, type of pavements.

Funding information: The authors state no funding involved.

Author contributions: All authors have accepted responsibility for the entire content of this manuscript and approved its submission.

Conflict of interest: The authors state no conflict of interest.

\section{References}

[1] Santika BB, Indrawati S, Suyatno, Yahya E. Noise Evaluation of Traffic Flows and Its Effect to Concentration Capability of the
Students in One of Private School in Surabaya. Procedia Eng. 2017;170(2017):274-9.

[2] Jamrah A, Al-Omari A, Sharabi R. Evaluation of traffic noise pollution in Amman, Jordan. Environ Monit Assess. 2006;120(13):499-525.

[3] Pandya GH. Urban Noise - A need for acoustic planning. Environ Monit Assess. 2001;67(3):379-88.

[4] Zannin PHT. Occupational noise in urban buses. Int J Ind Ergon. 2006;36(10):901-5.

[5] Freitas EF, Martins FF, Oliveira A, Segundo IR, Torres H. Traffic noise and pavement distresses: Modelling and assessment of input parameters influence through data mining techniques. Appl Acoust. 2018;138(March):147-55.

[6] Merska O, Mieczkowski P, Zymetka D. Low-noise Thin Surface Course - Evaluation of the Effectiveness of Noise Reduction. Transp Res Procedia. 2016;14:2688-97.

[7] Rajakumara HN, Mahalinge Gowda RM. Road traffic noise prediction model under interrupted traffic flow condition. Environ Model Assess. 2009;14(2):251-7.

[8] Khan J, Ketzel M, Jensen SS, Gulliver J, Thysell E, Hertel O. Comparison of Road Traffic Noise prediction models: CNOSSOS-EU, Nord2000 and TRANEX. Environ Pollut [Internet]. 2021;270:116240.

[9] European Environmental Agency. Noise in Europe 2014. 2014. 68 p.

[10] Zambon G, Roman HE, Smiraglia M, Benocci R. Monitoring and prediction of traffic noise in large urban areas. Appl Sci. $2018 ; 8(2)$.

[11] Tandel BN, Jem M. Assessment and Mlr Modeling of Urban Traffic Noise At Major Arterial Roads of Surat , India. 2013;7(4):1703-9.

[12] Berglund B, Lindvall T, Schwela DH. New Who Guidelines for Community Noise. Noise Vib Worldw. 2000;31(4):24-9.

[13] Sharifzadeh Mirshekarloo M, Tan CY, Yu X, Zhang L, Chen S, Yao K, Cui F, Pandit SM, Chong SH, Tan ST. Transparent piezoelectric film speakers for windows with active noise mitigation function. Appl Acoust [Internet]. 2018;137(February):90-7.

[14] Mishra RK, Parida M, Rangnekar S. Evaluation and analysis of traffic noise along bus rapid transit system corridor. Int J Environ Sci Technol. 2010;7(4):737-50.

[15] Nedic V, Despotovic D, Cvetanovic S, Despotovic M, Babic S. Comparison of classical statistical methods and artificial neural network in traffic noise prediction. Environ Impact Assess Rev. 2014;49:24-30.

[16] Jamrah A, Al-Omari A, Sharabi R. Evaluation of traffic noise pollution in Amman, Jordan. Environ Monit Assess. 2006;120(13):499-525.

[17] Licitra G, Teti L, Cerchiai M, Bianco F. The influence of tyres on the use of the CPX method for evaluating the effectiveness of a noise mitigation action based on low-noise road surfaces. Transp Res Part D Transp Environ. 2017;55:217-26.

[18] Ranpise R.B., Tandel B.N., Darjee C. (2021) Assessment and MLR Modeling of Traffic Noise at Major Urban Roads of Residential and Commercial Areas of Surat City. In: Kumar S., Kalamdhad A., Ghangrekar M. (eds) Sustainability in Environmental Engineering and Science. Lecture Notes in Civil Engineering, vol 93. Springer, Singapore. https://doi.org/10.1007/978-981-15-6887-9_21

[19] Debnath A, Singh PK. Environmental traffic noise modelling of Dhanbad township area - A mathematical based approach. Appl Acoust. 2018;129:161-72. 
[20] Lee PJ, Park SH, Jeong JH, Choung T, Kim KY. Association between transportation noise and blood pressure in adults living in multistorey residential buildings. Environ Int. 2019;132(April):105101.

[21] Gupta A, Gupta A, Jain K, Gupta S. Noise Pollution and Impact on Children Health. Indian J Pediatr. 2018;85(4):300-6.

[22] Deng Y, Cheng JCP, Anumba C. A framework for 3D traffic noise mapping using data from BIM and GIS integration. Struct Infrastruct Eng [Internet]. 2016;12(10):1267-80.

[23] Ruiz-Padillo A, Ruiz DP, Torija AJ, Ramos-Ridao Á. Selection of suitable alternatives to reduce the environmental impact of road traffic noise using a fuzzy multi-criteria decision model. Environ Impact Assess Rev. 2016;61:8-18.

[24] Ascigil-Dincer M, Yilmaz Demirkale S. Model development for traffic noise annoyance prediction. Appl Acoust. 2021;177:107909.

[25] Hamad K, Ali Khalil M, Shanableh A. Modeling roadway traffic noise in a hot climate using artificial neural networks. Transp Res Part D Transp Environ. 2017;53:161-77.
[26] Agarwal S, Swami BL. Comprehensive approach for the development of traffic noise prediction model for Jaipur city. Environ Monit Assess. 2011;172(1-4):113-20.

[27] Sonaviya DR, Tandel BN. Integrated road traffic noise mapping in urban Indian context. Noise Mapp. 2020;7(1):99-113.

[28] Van Renterghem T, Forssén J, Attenborough K, Jean P, Defrance J, Hornikx $M$, Kang J. Using natural means to reduce surface transport noise during propagation outdoors. Appl Acoust. 2015;92:86-101.

[29] Givargis S, Karimi H. A basic neural traffic noise prediction model for Tehran's roads. J Environ Manage [Internet]. 2010;91(12):2529-34.

[30] Licitra G, Gagliardi P, Fredianelli L, Simonetti D. Noise mitigation action plan of Pisa civil and military airport and its effects on people exposure. Appl Acoust. 2014;84:25-36. 